\title{
Time not right for Gallo
}

Washington \& Langen, West Germany

A PRESS conference at which Robert Gallo of the US National Cancer Institute was set to give his side of the dispute over who was first to discover the AIDS virus was abruptly cancelled last week after Gallo decided that "a story about this now would not help science".

The conference was to have been held at the newly opened Paul Ehrlich Institute in Langen where Gallo was attending a scientific meeting. Gallo said he wanted to clear his name in West Germany where the press had repeated statements from an article in the French newspaper Le Monde which quoted Luc Montagnier of the Pasteur Institute as appealing to Gallo to "at last accept the evidence" and admit the Pasteur Institute as the true source of the AIDS virus.

In addition to enraging Gallo, Montagnier's statements may breach a 1987 treaty between France and the United States (see Nature 344, 481; 5 April 1990) which named Gallo and Montagnier as "co-discoverers" of the AIDS virus and forbade both Gallo and Montagnier from contradicting the "scientific history" laid out in the treaty.

Gallo also said that he decided not to hold the press conference because he did not want to prejudice the inquiry being conducted by the US National Institutes of Health (NIH). Gallo said that he would be more than willing to talk "in a few weeks." First, he said, "I must go through this process to its completion. Then I will show you my material." The NIH inquiry (which Gallo insists is "interviews" rather than "investigation") was stimulated by a 16-page article by John Crewdson in the Chicago Tribune newspaper which repeated allegations that the AIDS virus isolated by Gallo may have come from samples provided by Montagnier. According to a letter from NIH to the US Congressional Subcommittee on Oversight and Investigations, NIH is "assembling and analyzing information" relevant to issues raised in Crewdson's article.

Underpinning these issues is the key question of whether the virus isolated in Gallo's laboratory at the end of 1983 , then known as HTLV-3, is the same as that isolated from a French AIDS patient by Montagnier earlier that year. Montagnier sent a sample of his virus, designated LAV, to Gallo in September 1983 and, in a patent dispute in 1985 , claimed that Gallo had used LAV grown from that sample to develop an antibody test.

Against the now known background of genetic variability of the virus, the published genetic sequences of HTLV-3 and LAV are remarkably similar, with no two isolates having exactly the same genetic make-up. The virus also mutates rapidly

in infected patients, so viral isolates taken from one patient at different times may differ markedly. This fuelled suspicion about the source of HTLV-3,

The sequence similarity led Crewdson to conclude that Gallo obtained HTLV-3 from cultures of LAV, either deliberately or in error. According to Crewdson, Gallo has always maintained that LAV was not grown successfully in his laboratory. But from his analysis of laboratory notebooks and memos sent to Gallo from his chief virologist, Crewdson traces a route through many gaps in the record - by which LAV could have been grown for long periods of time in the laboratory, eventually re-emerging as HTLV-3.

Crewdson alleges that Gallo knew about LAV's relationship to AIDS before he published his own discovery of HTLV3 in 1984. This, and questions of exactly when Gallo's researchers first embarked on isolating HTLV-3, are the focus of the NIH inquiry:

- According to Crewdson, Gallo, in a sworn statement to the patent committee in 1985, said that before the patent for his antibody test was granted in May 1985, he had seen no evidence linking LAV to AIDS. But Crewdson contends that by April 1984, Gallo had been told by the Pasteur group that its LAV-based antibody test worked as well in trials conducted by the US Centres for Disease Control as his own test developed from HTLV- 3. EPIDEMIOLOGY

\section{New data to reveal leukaemia links?}

\section{London}

THE factors underlying the occurrence of localized clusters of leukemia cases will come in for further scrutiny following the announcement of the results of a survey that shows such clusters are uncommon in England and Wales.

The survey, published yesterday, is the work of Ray Cartwright and colleagues at the Leukaemia Research Fund (LRF)'s clinical epidemiology centre in Leeds. It catalogues the distribution of leukaemia and lymphoma cases from 1984 to 1988 among a population of 15 million people.

The authors do not attempt to explain the occurrence of individual clusters, such as the tenfold excess of cases near the Sellafield nuclear plant. In the absence of a general pattern of clustering, epidemiologists may be justified in looking in detail for causes of particular clusters. Competing theories include the Gardner hypothesis that high paternal radiation doses may cause leukaemia in children (see Nature 343,$679 ; 22$ February 1990) and variants of the theory that viruses are to blame.

The new survey is the most comprehensive to date of leukaemia incidence in the
- Crewdson claims that, in 1983, Gallo's researchers themselves discovered that HTLV -3 and LAV are immunologically similar, but did not publish the results. Despite Gallo's denial to Crewdson that detailed studies of LAV were carried out in his lab, Gallo published a letter in Science showing electron micrographs of LAV taken at that time, one of which had been inadvertently labelled as HTLV-3 in an earlier Science paper.

- In a letter to Nature in 1986, Gallo claimed that he obtained the first isolates of HTLV-3 well before September 1983, when the shipment of LAV arrived in his laboratory. Crewdson notes inconsistencies between data in that letter and in an earlier paper by Gallo.

One issue that NIH has specifically said it will investigate is a deletion in a letter obtained by James Swire, a lawyer representing the Pasteur Institute. The letter had been written by an electron microscopist who had been studying cells containing viruses from Gallo's laboratory. According to Crewdson, the original version of the letter said that the French virus had been successfully photographed growing in a type of $\mathrm{T}$ cell that Gallo claimed had never been used for culturing LAV in his laboratory. But when, in response to a Freedom of Information Act request in December 1985, a copy of the letter was sent to Swire, Crewdson claims that all mention of LAV had been deleted.

The NIH committee of inquiry is expected to conclude by mid-summer.

David Concar \& Steven Dickman

United Kingdom, and gives cancer epidemiologists a sound database to link leukaemia incidence with putative causal factors. The LRF team are now looking at a number of possibilities, including the correlation of indoor radon exposure with the distribution of the diseases. In the survey, they note that two forms of leukaemia "display a tendency towards high rates in the extreme south-west", where indoor radon levels are the highest in the United Kingdom.

Their data should shed light on the controversial link between exposure to radioactive radon gas and leukaemia, suggested by a team of physicists from Bristol University (see Nature 345, 4; 3 May 1990). The Bristol study correlated average indoor radon concentrations with cancer records across 14 countries. But in some cases, the geographical areas covered by the cancer records and radon data did not overlap completely. The LRF data will allow a finer-grained correlation for better defined geographical areas.

Peter Aldhous

"Leukaemia and Lymphoma: an atlas of distribution within areas of England and Wales 1984-1988 "is published by the Leukaemia Research Fund. 